\title{
Nitrogen-Doped Graphene as Efficient Metal-Free Electrocatalyst for Oxygen Reduction in Fuel Cells
}

\author{
Liangti Qu, ${ }^{+, \pi}$ Yong Liu, ${ }^{\neq, \pi, *}$ Jong-Beom Baek, ${ }^{\S}$ and Liming Dai ${ }^{\perp, *}$ \\ ${ }^{\dagger}$ Department of Chemistry, School of Science, Beijing Institute of Technology, Beijing 100081, P. R. China, `Biomedical Engineerig Academy, School of Ophthalmology and \\ Optometry, Wenzhou Medical College, 270 Xueyuan Road, Wenzhou, Zhejiang 325027, China, ${ }^{5}$ School of Energy Engineering, Ulsan National Institute of Science and \\ Technology (UNIST), No. 685 Namyoedong, Junggu, Ulsan, Republic of Korea 681-800, and ${ }^{\perp}$ Department of Chemical Engineering, Case Western Reserve University, \\ 10900 Euclid Avenue, Cleveland, Ohio 44106. "These authors contributed equally.
}

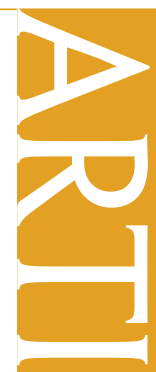

$\mathrm{P}$ latinum (Pt) nanoparticles have long been regarded as the best catalyst for the oxygen reduction reaction (ORR) in fuel cells, though the Pt-based electrode still suffers from its susceptibility to timedependent drift and $\mathrm{CO}$ deactivation. ${ }^{1-3}$ Furthermore, the high cost of the Pt catalysts, together with the limited reserves of $\mathrm{Pt}$ in nature, has been shown to be the major "showstopper" to mass market fuel cells for commercial applications. That is why the large-scale practical application of fuel cells has not been realized, though alkaline fuel cells with platinum as an ORR electrocatalyst were developed for the Apollo lunar mission in the 1960s. ${ }^{4}$ Along with recent intensive research efforts in reducing or replacing Ptbased electrodes in fuel cells, ${ }^{3,5-11}$ we have found that vertically aligned nitrogencontaining carbon nanotubes (VA-NCNTs) produced by pyrolysis of iron(II) phthalocyanine (a metal heterocyclic molecule containing nitrogen), ${ }^{12}$ in either the presence or absence of additional $\mathrm{NH}_{3}$ vapor, ${ }^{3}$ could act as effective metal-free ORR electrocatalysts. The metal-free VA-NCNTs were shown to catalyze a four-electron ORR process free from CO "poisoning" with a 3-time higher electrocatalytic activity, smaller crossover effect, and better long-term operation stability than that of commercially available Pt-based electrodes (C2-20, 20\% platinumonVulcanXC-72R; E-TEK) in alkaline electrolytes. ${ }^{3}$ On the basis of the experimental observations and quantum mechanics calculations, we attributed the improved catalytic performance to the electronaccepting ability of the nitrogen atoms, which creates a net positive charge on adjacent carbon atoms in the nanotube carbon plane of VA-NCNTs to readily attract elec-
ABSTRACT Nitrogen-doped graphene ( $\mathrm{N}$-graphene) was synthesized by chemical vapor deposition of methane in the presence of ammonia. The resultant $\mathrm{N}$-graphene was demonstrated to act as a metal-free electrode with a much better electrocatalytic activity, long-term operation stability, and tolerance to crossover effect than platinum for oxygen reduction via a four-electron pathway in alkaline fuel cells. To the best of our knowledge, this is the first report on the use of graphene and its derivatives as metal-free catalysts for oxygen reduction. The important role of $\mathrm{N}$-doping to oxygen reduction reaction (ORR) can be applied to various carbon materials for the development of other metal-free efficient ORR catalysts for fuel cell applications, even new catalytic materials for applications beyond fuel cells.

KEYWORDS: graphene $\cdot \mathrm{N}$-doping · oxygen reduction $\cdot$ fuel cell

trons from the anode for facilitating the ORR. ${ }^{3}$ Uncovering this new ORR mechanism in nitrogen-doped carbon nanotube electrodes is significant as the same principle could be applied to the development of various other metal-free efficient ORR catalysts for fuel cell applications.

The recent discovery of graphene has opened up a new era of 2-dimensional (2D) fundamental science and potential technology. ${ }^{13-15}$ As mother of all graphitic forms, graphene is a building block for carbon materials of all other dimensionalities, such as OD buckyballs, 1D nanotubes, and 3D graphite. Having many similarities to carbon nanotubes (CNTs) in structure and property, including its high aspect ratio (the ratio of lateral size to thickness), large surface, rich electronic states, and good mechanical properties, graphene is an attractive candidate for potential uses in many areas where the CNTs have been exploited. Superior to CNTs, the one atomic-thick graphene sheets with a 2D planar geometry will further facilitate electron transport, ${ }^{16}$ and hence the more effective electrode materials.
*Address correspondence to yongliu1980@hotmail.com,

Received for review December 18, 2009 and accepted February 06, 2010.

Published online February 15, 2010. $10.1021 / \mathrm{nn} 901850 \mathrm{u}$

() 2010 American Chemical Society liming.dai@case.edu. 


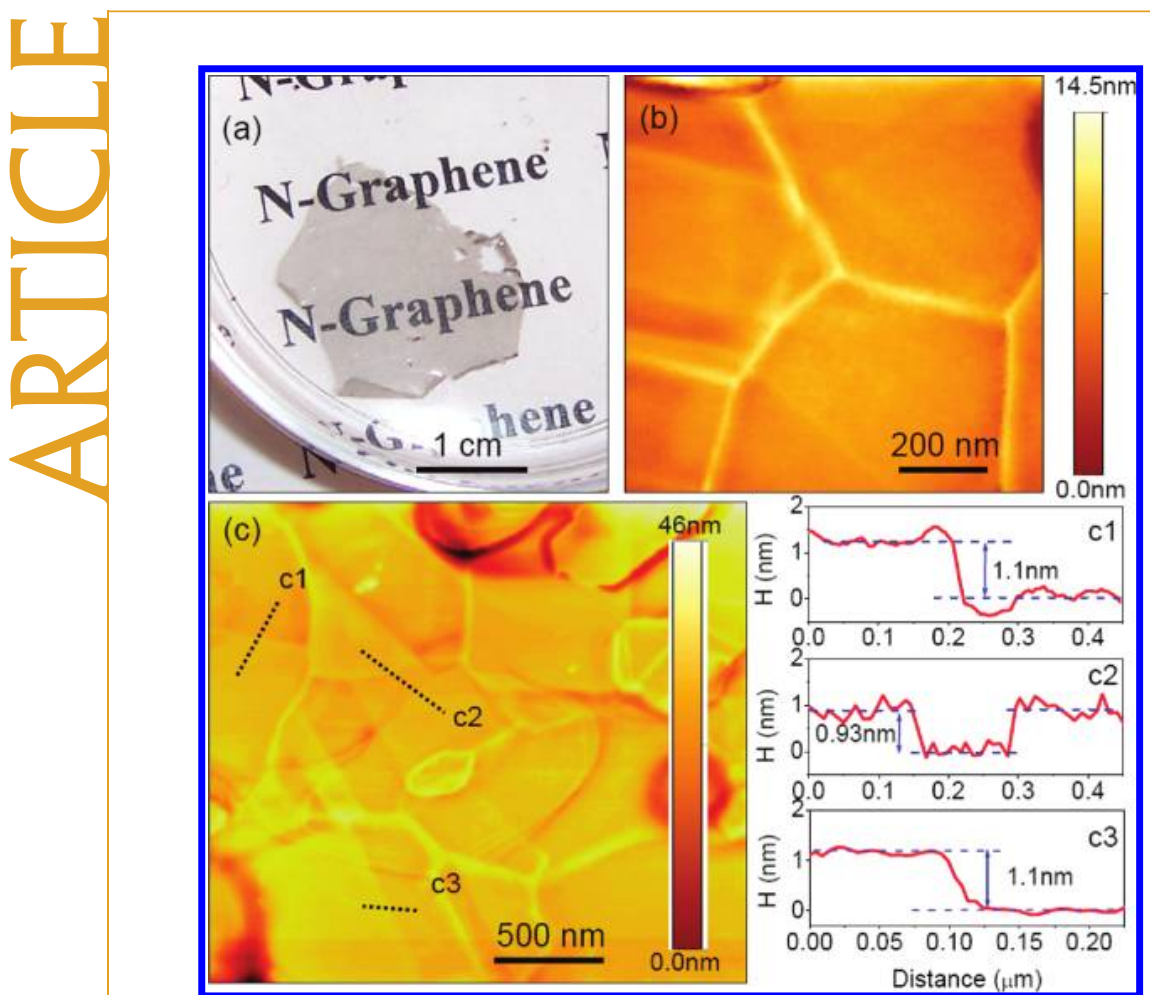

Figure 1. (a) A digital photo image of a transparent $\mathrm{N}$-graphene film floating on water after removal of the nickel layer by dissolving in an aqueous acid solution; (b, c) AFM images of the N-graphene film and the correpsonding height analyses along the lines marked in the AFM image ( $1-c 3$ in panel c).

Although CNTs and their N-doped counterparts have been synthesized and studied for some years, the large-scale preparation of graphene sheets by chemical vapor deposition (CVD) is only the recent development. ${ }^{17,18}$ More recently, attempts have been

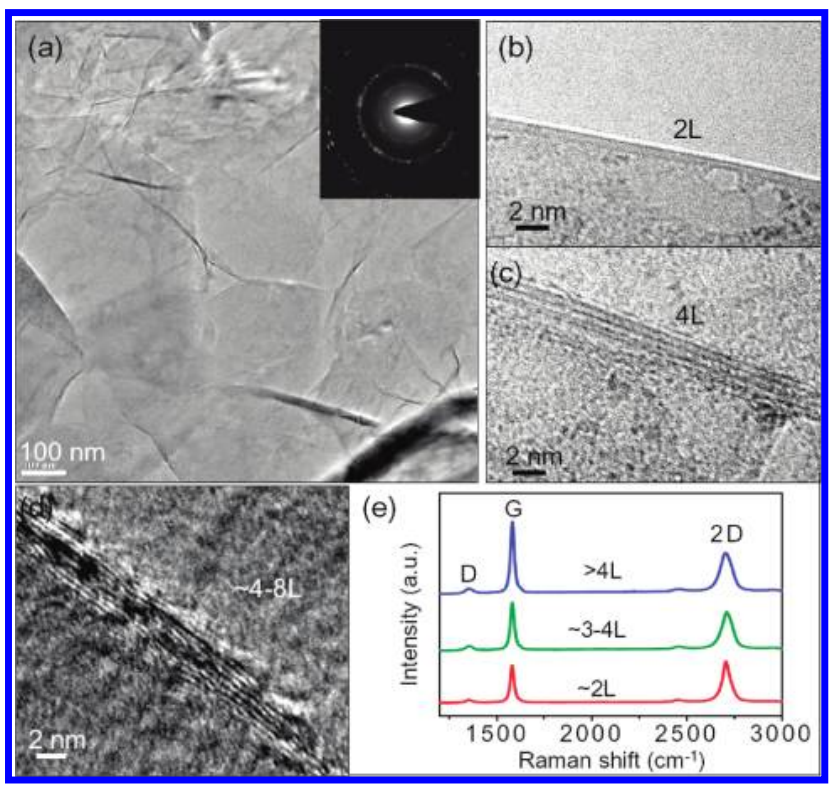

Figure 2. TEM and Raman analyses of the N-graphene films. (a) Low-magnification TEM image showing a few layers of the CVDgrown N-graphene film on a grid. Inset shows the corresponding electron diffraction pattern. $(b-d)$ High magnification TEM images showing edges of the $\mathrm{N}$-graphene film regions consisting of (b) 2 , (c) 4, and (d) ca. 4-8 graphene layers. (e) The corresponding Raman spectra of the $\mathrm{N}$-graphene films of different graphene layers on a $\mathrm{SiO}_{2} / \mathrm{Si}$ substrate (Methods). made to introduce heteroatoms (e.g., nitrogen) into graphene sheets for modulation of their electronic properties. ${ }^{19}$ As far as we are aware, however, the possibility for nitrogen-containing graphene sheets ( $\mathrm{N}$-graphene, we designate the $\mathrm{N}$-free graphene as $\mathrm{C}$-graphene for convenience) to be used as catalysts for the ORR process in fuel cells has not been exploited. In the present study, we investigated the CVD-deposited $\mathrm{N}$-graphene sheets for ORR at the cathode in alkaline fuel cells. As we shall see later, the $\mathrm{N}$-graphene showed a much better electrocatalytic activity, long-term operation stability, and tolerance to crossover and poison effects than the commercially available platinum-based electrodes (C2-20, 20\% platinumonVulcanXC-72R; E-TEK) for oxygen reduction.

In this study, we used a modified CVD process $^{17}$ for the synthesis of $\mathrm{N}$-graphene films. Briefly, a thin layer of nickel $(\sim 300 \mathrm{~nm})$ was deposited on a $\mathrm{SiO}_{2} / \mathrm{Si}$ substrate by sputter coating. The Ni-coated $\mathrm{SiO}_{2} / \mathrm{Si}$ wafer was then heated up to $1000{ }^{\circ} \mathrm{C}$ within a quartz tube furnace under a high purity argon atmosphere. Thereafter, a nitrogen-containing reaction gas mixture $\left(\mathrm{NH}_{3}\right.$ : $\mathrm{CH}_{4}: \mathrm{H}_{2}: \mathrm{Ar}=10: 50: 65: 200$ standard cubic centimeters per minute) was introduced into the quartz tube and kept flowing for 5 min, followed by purging with a flow of $\mathrm{NH}_{3}$ and Ar only for another 5 min. The sample was then rapidly moved out from the furnace center $\left(1000^{\circ} \mathrm{C}\right)$ under Ar protection. The resultant $\mathrm{N}$-graphene film can be readily etched off from the substrate by dissolving the residual $\mathrm{Ni}$ catalyst layer in an aqueous solution of $\mathrm{HCl}_{1}{ }^{17,18}$ allowing the freestanding $\mathrm{N}$-graphene sheets to be transferred onto substrates suitable for subsequent investigation.

Figure 1a shows a free-standing film of $c a .4 \mathrm{~cm}^{2}$ in size floating on water after removing the nickel layer by $\mathrm{HCl}$. Just like CVD-synthesized C-graphene films, ${ }^{17}$ the $\mathrm{N}$-graphene film thus produced is flexible and transparent, consisting of only one or a few layers of the graphite sheets. A scanning electron microscope (SEM) image of this $\mathrm{N}$-graphene film shows a flat flake-like surface (Supporting Information, Figure S1). Atomic force microscopic (AFM) scanning image given in Figure 1b shows a smooth surface with wrinkles due to its pliability. The layered structure revealed in Figure 1c enabled us to directly analyze the layer thickness, which was found to be in the range of $0.9-1.1 \mathrm{~nm}$, consistent with previous studies. ${ }^{14,20-23}$

The substrate-free N-graphene sheets can be directly transferred onto TEM grids for further characterization. As shown in Figure 2a, TEM images also revealed flat flakes, resembling those seen in Figures $1 b, c$. Unlike most C-graphene films of symmetric hexagonal diffraction patterns, ${ }^{18,24}$ electron diffraction of the N-graphene film (inset of Figure 2a) shows a 
ringlike diffraction pattern with dispersed bright spots. The above observed difference indicates that the otherwise crystalline graphene sheets became partially misorientated in the $\mathrm{N}$-graphene film due to structure distortions caused by the intercalation of nitrogen atoms into its graphitic plans, as also seen for N-doped CNTs. ${ }^{3}$ The cross-sectional view of the suspended edge of the as-synthesized $\mathrm{N}$-graphene film shows, once again, only a few layers (typically, 2-8 layers) of graphene sheets (Figures 2b-d). Adjacent interlayer distances in the $\mathrm{N}$-graphene film were measured to be $0.3-0.4 \mathrm{~nm}$, close to the $d$-spacing of (002) crystal plane $(0.335 \mathrm{~nm})$ of bulk graphite with slight distortion. ${ }^{25}$

Raman spectra of the as-synthesized N-graphene sheets with different layer numbers are given in Figure 2e. Similar to C-graphene films, ${ }^{17,18,24}$ the $G$ band and 2D band of the N-graphene samples were found to be sensitive to the layer number. For comparison, Raman spectra for both the N-graphene and C-graphene films were given in Supporting Information, Figure S2, which revealed a relatively higher $\mathrm{D}$ band for the $\mathrm{N}$-graphene than that of C-graphene film due to structural distortion caused by $\mathrm{N}$-doping. However, the very low value of $0.06-0.25$ for the $I_{D} / I_{G}$ (a peak intensity ratio of the $D$ to $\mathrm{G}$ band ${ }^{18}$ indicates that the $\mathrm{N}$-graphene layers remain a high crystalline quality. This is further evidenced by the X-ray diffraction (XRD) profiles shown in Supporting Information, Figure S3, in which a pronounced (002) peak at $26^{\circ}$ characteristic of C-graphene was also seen for $\mathrm{N}$-graphene. The broad background band centered at $26^{\circ}$ can be attributable to the presence of intercalated "N defects" in the N-graphene structure. The slight shift of the (002) peak from $26.5^{\circ}$, characteristic of C-graphene, to $26.1^{\circ}$ for $\mathrm{N}$-graphene seen in the inset of Supporting Information, Figure S3 suggests that the $\mathrm{N}$-doping has also led to an increased interlayer spacing for the $\mathrm{N}$ - graphene film. From the (002) diffraction peak positions, we calculated the $d$-spacing for the $\mathrm{N}$-graphene film to be $3.41 \AA$. This value is in good agreement with the TEM measurements, but still slightly higher than that of C-graphene film (3.36 $\AA$ ) (Supporting Information, Figure S3) and graphite (3.35 Å). ${ }^{26}$

To probe nitrogen atoms in the N-graphene structure, we carried out X-ray photoelectron spectroscopic (XPS) measurements. As can be seen in Figure 3, the XPS survey spectrum for the N-graphene shows a predominant narrow graphitic $\mathrm{C} 1 \mathrm{~s}$ peak at $284.2 \mathrm{eV}, 27,28$ along with a N 1s peak at ca.400 eV. Figure S4 shows the XPS survey spectra for both the N-graphene and $\mathrm{C}$-graphene over a wide range of binding energies $(0-1000 \mathrm{eV})$. In addition to the $\mathrm{C} 1 \mathrm{~s}$ and $\mathrm{N}$ 1s peaks, an $\mathrm{O} 1 \mathrm{~s}$ peak at ca. $540 \mathrm{eV}$ was also observed for both $\mathrm{N}$-graphene and C-graphene, ${ }^{29,30}$ possibly due to the incorporation physically adsorbed oxygen as in the case with CNTs. ${ }^{28,31}$ Thus, the higher $\mathrm{O}$ 1s peak relative to the corresponding $\mathrm{C}$ 1s peak seen for the $\mathrm{N}$-graphene than

www.acsnano.org

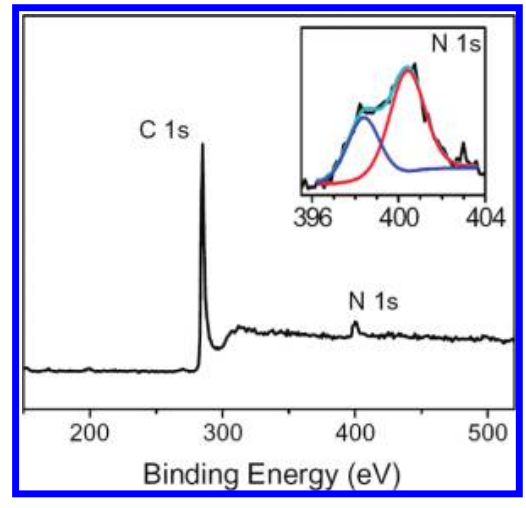

Figure 3. XPS survey for the as-synthesized N-graphene film. Inset shows the high-resolution $\mathrm{N} 1 \mathrm{~s}$ spectrum.

that of the $\mathrm{C}$-graphene suggests a stronger $\mathrm{O}_{2}$ adsorption on the former, an additional advantage as the ORR electrode. The absence of any Ni peak in the XPS spectrum for the $\mathrm{N}$-graphene clearly indicates that the $\mathrm{Ni}$ catalyst residues, if any, have been completely removed by the $\mathrm{HCl}$ solution. The high resolution XPS N 1s spectrum given in the inset of Figure 3 reveals the presence of both pyridine-like $(\sim 398.3 \mathrm{eV})$ and pyrrolic ( $\sim 400.5 \mathrm{eV}$ ) nitrogen atoms within the graphene structure, ${ }^{32-35}$ both play roles in the ORR process. ${ }^{3}$ Similar to $\mathrm{N}$-doped carbon nanotubes, ${ }^{3,36}$ therefore, $\mathrm{N}$ atoms have been incorporated into the graphene hexagon rings, as reflected by the pyridine-like XPS N 1s peak at ca. $398.3 \mathrm{eV}$. The N/C atomic ratio was calculated to be ca. 4 atomic \%, which is close to that of the $\mathrm{N}$-doped carbon nanotubes used for ORR study in our previous work. $^{3}$

We performed the rotating ring-disk electrode (RRDE) voltammograms to investigate electrocatalytic activities of the $\mathrm{N}$-graphene film for ORR in air-saturated $0.1 \mathrm{M} \mathrm{KOH}$ electrolyte. The C-graphene film prepared under the same CVD conditions, but without the introduction of $\mathrm{NH}_{3}$ gas, and commercially available Ptloaded carbon (Vulcan XC-72R) supported by a glassy carbon electrode $(\mathrm{Pt} / \mathrm{C})$ were also investigated for comparison. Just like the pure CNT electrode without $\mathrm{N}$-doping, ${ }^{3}$ the $\mathrm{C}$-graphene electrode shows a twostep, two-electron process for oxygen reduction with the onset potential of about -0.45 and $-0.7 \mathrm{~V}$ (Figure 4a). Unlike the C-graphene electrode, the N-graphene electrode (Figure 4a) exhibited a one-step, four-electron pathway for the ORR, as is the case with N-doped CNTs. ${ }^{3}$ The steady-state catalytic current density at the $\mathrm{N}$-graphene electrode was found to be $c a .3$ times higher than that of the $\mathrm{Pt} / \mathrm{C}$ electrode over a large potential range (Figure 4a). The transferred electron number ( $n$ ) per oxygen molecule at the N-graphene electrode was calculated by Koutecky - Levich $(\mathrm{K}-\mathrm{L})$ equation ${ }^{37}$ to be $3.6-4$ at the potential ranging from -0.4 to $-0.8 \mathrm{~V}$ (Supporting Information, Figure S5). These results indicate that the $\mathrm{N}$-graphene electrode, 


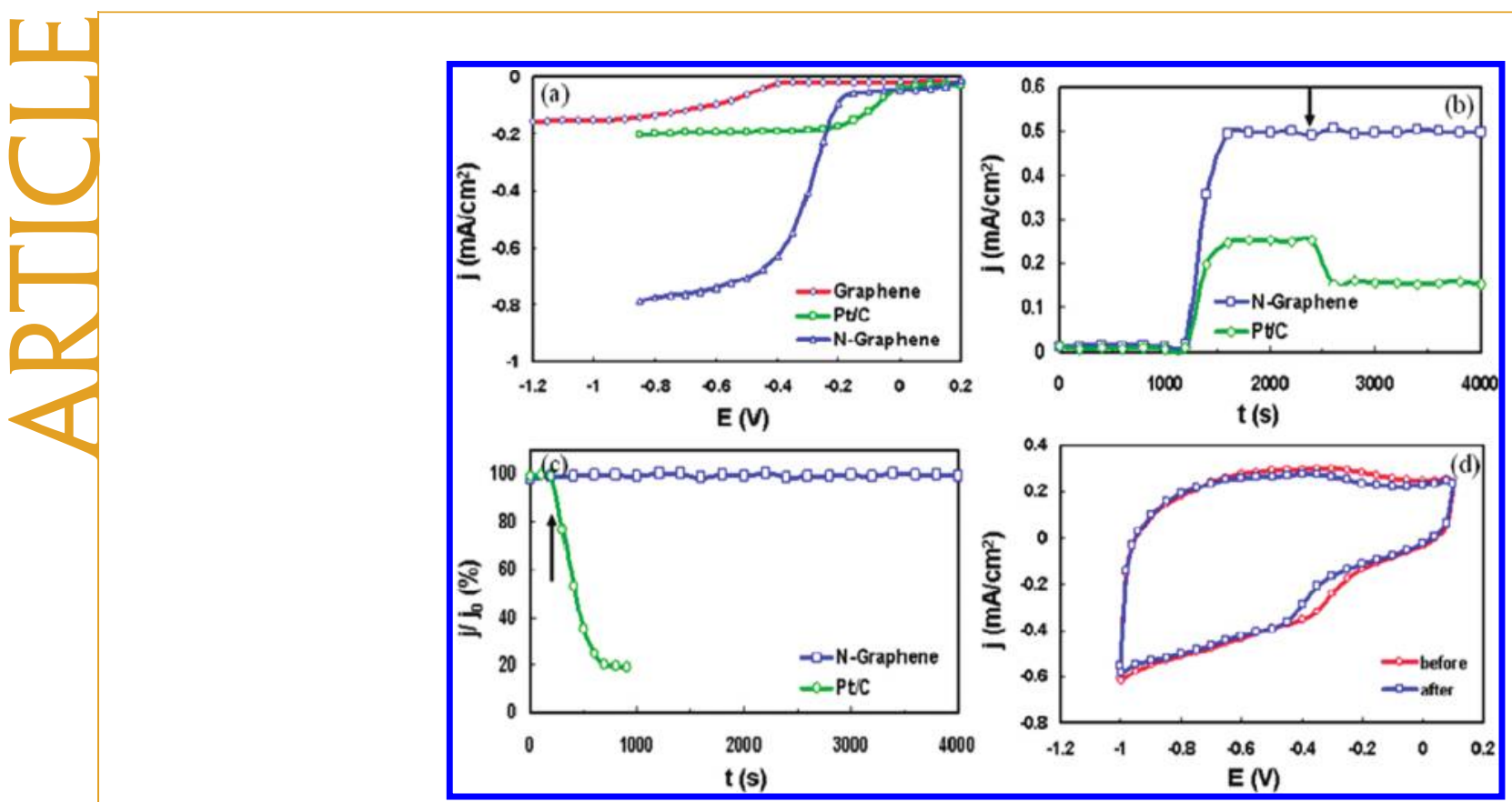

Figure 4. (a) RRDE voltammograms for the ORR in air-saturated $0.1 \mathrm{M} \mathrm{KOH}$ at the C-graphene electrode (red line), $\mathrm{Pt} / \mathrm{C} \mathrm{elec-}$ trode (green line), and N-graphene electrode (blue line). Electrode rotating rate: $1000 \mathrm{rpm}$. Scan rate: $0.01 \mathrm{~V} / \mathrm{s}$. Mass (graphene) $=$ $\operatorname{Mass}_{(\mathrm{PtC})}=\operatorname{Mass}_{(\mathrm{N} \text {-grapene) }}=7.5 \mu \mathrm{g}$. (b) Current density $(\mathrm{j})$-time $(t)$ chronoamperometric responses obtained at the Pt/C (circle line) and $\mathrm{N}$-graphene (square line) electrodes at $-0.4 \mathrm{~V}$ in air saturated $0.1 \mathrm{M} \mathrm{KOH}$. The arrow indicates the addition of $2 \%$ $(\mathrm{w} / \mathrm{w})$ methanol into the air-saturated electrochemical cell. (c) Current (j)-time $(t)$ chronoamperometric response of $\mathrm{Pt} / \mathrm{C}$ (circle line) and $\mathrm{N}$-graphene (square line) electrodes to CO. The arrow indicates the addition of $10 \%(\mathrm{v} / \mathrm{v}) \mathrm{CO}$ into air saturated $0.1 \mathrm{M} \mathrm{KOH}$ at $-0.4 \mathrm{~V} ; j_{0}$ defines the initial current. (d) Cyclic voltammograms of $\mathrm{N}$-graphene electrode in air saturated $0.1 \mathrm{M} \mathrm{KOH}$ before (circle line) and after (square line) a continuous potentiodynamic swept for 200000 cycles at room temperature $\left(25^{\circ} \mathrm{C}\right)$. Scan rate: $0.1 \mathrm{~V} / \mathrm{s}$.

similar to its CNT counterpart, ${ }^{3}$ is a promising metalfree catalyst for the ORR in an alkaline solution.

The N-graphene electrode was further exposed to fuel molecules (e.g., methanol) and $\mathrm{CO}$ to test the possible crossover and poison effects. ${ }^{38,39} \mathrm{We}$ measured electrocatalytic selectivity of the $\mathrm{N}$-graphene electrode against the electro-oxidation of various commonly used fuel molecules, including hydrogen gas, glucose, and methanol (Figure 4b). Also included in Figure $4 \mathrm{~b}$ is the corresponding current density $(j)$-time $(t)$ chronoamperometric response at a $\mathrm{Pt} / \mathrm{C}$ electrode for comparison. As shown in Figure 4b, a 40\% decrease in current appears at the $\mathrm{Pt} / \mathrm{C}$ electrode upon the addition of $2 \%(\mathrm{w} / \mathrm{w})$ methanol. However, the strong and stable amperometric response from the ORR on the $\mathrm{N}$-graphene electrode remained unchanged after the addition of hydrogen gas, glucose, and methanol (Figure 4b). Such high selectivity of the N-graphene electrode toward the ORR and remarkably good tolerance to crossover effect can be attributed to the much lower ORR potential than that required for oxidation of the fuel molecules. ${ }^{3,40}$ To examine the effect of $\mathrm{CO}$ on the electrocatalytic activity of the $\mathrm{N}$-graphene electrode, a $10 \%(\mathrm{v} / \mathrm{v}) \mathrm{CO}$ in air was introduced into the electrolyte. The $\mathrm{N}$-graphene electrode was insensitive to CO (Figure 4c), whereas the Pt/C electrode was rapidly poisoned under the same conditions. We also performed continuous potential cycling to in- vestigate the stability of the $\mathrm{N}$-graphene electrode toward ORR. As can be seen in Figure 4d, no obvious decrease in current was observed after 200000 continuous cycles between -1.0 and $0 \mathrm{~V}$ in airsaturated $0.1 \mathrm{M} \mathrm{KOH}$.

In summary, we have developed a facile CVD approach for the large-area synthesis of $\mathrm{N}$-graphene films, which can be readily transferred onto various substrates. The high-quality $\mathrm{N}$-graphene films thus formed were evidenced by AFM, TEM, Raman, XRD, and XPS measurements. The $\mathrm{N}$-graphene film shows superb performance for oxygen reduction reaction associated with alkaline fuel cells. The steady-state catalytic current at the $\mathrm{N}$-graphene electrode was found to be ca. 3 times higher than that at the $\mathrm{Pt} / \mathrm{C}$ electrode over a large potential range. The long-term stability, tolerance to crossover, and poison effect are also better than $\mathrm{Pt} / \mathrm{C}$ for oxygen reduction in alkaline electrolyte. It is notable that the $\mathrm{N}$-doped graphene film possesses remarkable electrocatalytic properties for ORR similar to that of nitrogen-containing vertically aligned carbon nanotubes. ${ }^{3}$ The ease with which graphene materials and their $\mathrm{N}$-doped derivatives can be produced by various low-cost large-scale methods, including the chemical vapor deposition, chemical reduction of graphite oxide, ${ }^{14,20}$ exfoliation of graphite, ${ }^{21}$ microwave plasma reaction, ${ }^{41}$ and atmospheric pressure graphitization of silicon carbide, ${ }^{42}$ suggests considerable room for costeffective preparation of metal-free efficient graphene- 
based catalysts for oxygen reduction. Furthermore, this work clearly indicates that the important role of $\mathrm{N}$-doping to ORR demonstrated with nitrogen-doped carbon nanotubes and $\mathrm{N}$-graphene can be applied to other carbon materials for the development of various other metal-free efficient ORR catalysts for fuel cell applications, even new catalytic materials for applications beyond fuel cells.

\section{METHODS}

Preparation of $\mathrm{N}-\mathrm{Graphene} \mathrm{Films.} \mathrm{A} \mathrm{thin} \mathrm{layer} \mathrm{of} \mathrm{nickel} \mathrm{film}(\sim 300$ $\mathrm{nm}$ ) was deposited on a $\mathrm{SiO}_{2} / \mathrm{Si}$ substrate by sputter coating, which was then heated up to $1000{ }^{\circ} \mathrm{C}$ within a quartz tube under a high purity argon atmosphere. Thereafter, a nitrogencontaining reaction gas mixture $\left(\mathrm{NH}_{3}: \mathrm{CH}_{4}: \mathrm{H}_{2}: \mathrm{Ar}=10: 50: 65: 200\right.$ standard cubic centimeters per minute) was introduced into the quartz tube and kept flowing for $5 \mathrm{~min}$, followed by purging with a flow of $\mathrm{NH}_{3}$ and Ar only for another $5 \mathrm{~min}$. The sample was then rapidly moved out from the furnace center $\left(1000^{\circ} \mathrm{C}\right)$ under Ar protection. The resultant $\mathrm{N}$-containing graphene (designated as: $\mathrm{N}$-graphene) film can be readily etched off from the substrate by dissolving the $\mathrm{Ni}$ catalyst residues in an aqueous solution of $\mathrm{HCl}(1 \mathrm{M})$, allowing the free-standing $\mathrm{N}$-graphene sheets to be transferred onto substrates suitable for subsequent investigation. For comparison, the pure graphene film was synthesized by the same procedure without $\mathrm{NH}_{3}$ flow. ${ }^{17}$

Electrode Preparation. N-graphene and pure graphene (designated as C-graphene) nanofilms floating on DI water were transferred onto a glassy carbon (GC) disk electrode $(3 \mathrm{~mm}$ in diameter, Pine Research Instrumentation). The electrode was dried at $40^{\circ} \mathrm{C}$ under vacuum for $60 \mathrm{~min}$. Electrodes for rotating ring-disk electrode (RRDE) voltammogram measurements were prepared on a $5 \mathrm{~mm}$ diameter GC disk electrode (Pine Research Instrumentation). The commercialized Platinum loaded carbon catalysts (PtC, C2-20, 20\% HP Pt on Vulcan XC-72R, E-TEK Division, PEMEAS Fuel Cell Technologies) electrode was prepared according to the procedure described elsewhere. ${ }^{3}$ Typically, $1 \mathrm{mg} / \mathrm{mL}$ $\mathrm{PtC}$ dispersion in ethanol was prepared using ultrasonication. A $7.5 \mu \mathrm{g}$ portion of PtC was introduced onto the GC electrode using a microsyringe.

Characterization. Scanning electron microscopy (SEM) and transmission electron microscopy (TEM) images were recorded on a Hitachi S4800-F high-resolution SEM and H-7600 TEM unit (Hitachi, Japan), respectively. Tapping-mode atomic force microscopy (AFM) measurements were preformed on Nano-R2 SPM system (Pacific Nanotechnology). X-ray photoelectron spectroscopic (XPS) measurements were performed on a VG Microtech ESCA 2000 using a monochromic Al X-ray source. X-ray diffraction patterns of $\mathrm{C}$-graphene and $\mathrm{N}$-graphene films were performed on a Rigaku MiniFlex II diffractometer with Cu K $\alpha$ radiation $(1.406 \AA)$. The diffraction data were collected in step scans, with a step size of $0.05^{\circ}(2 \theta)$ and a count time of $2 \mathrm{~s}$ per step between 10 and $100^{\circ}(2 \theta)$. Raman microspectroscopy was carried out on a Renishaw inVia unit using the Ar ion laser with an excitation wavelength of $514.5 \mathrm{~nm}$.

Electrochemical measurements were performed on a computer-controlled potentiostat (CHI 760C, CH Instrument, USA) with a three-electrode cell equipped with gas flow systems. A N-graphene, C-graphene, or Pt/C electrode was used as working electrode while an $\mathrm{Ag} / \mathrm{AgCl}$ (4 M KCl-filled) electrode as reference and a platinum wire as counterelectrode.

Acknowledgment. We thank the support from AFOSR (FA9550-09-1-0331), WCU Project through UNIST from the Ministry of Education, Science and Technology in Korea, Beijing Institute of Technology, and MOST of P.R. China (2009DFB30380) and R\&D Project of Zhejiang Province of P.R. China (2009C13019) through Wenzhou Medical College.

Supporting Information Available: Additional SEM image, Raman, XRD, XPS, and $j-V$ curves for $\mathrm{N}$-graphene and $\mathrm{C}$-graphene are given in Figures $\mathrm{S} 1-\mathrm{S} 5$. This material is available free of charge via the Internet at http://pubs.acs.org.

\section{REFERENCES AND NOTES}

1. Winter, M.; Brodd, R. J. What Are Batteries, Fuel Cells, and Supercapacitors. Chem. Rev. 2004, 104, 4245-4269.

2. Yu, X.; Ye, S. Recent Advances in Activity and Drability Enhancement of Pt/C Catalytic Cathode in PEMFC Part II: Degradation Mechanism and Durability Enhancement of Carbon Supported Platinum Catalyst. J. Power Sources 2007, 172, 145-154.

3. Gong, K.; Du, F.; Xia, Z.; Dustock, M.; Dai, L. NitrogenDoped Carbon Nanotube Arrays with High Electrocatalytic Activity for Oxygen Reduction. Science 2009, 323, 760-764, and references cited therein.

4. Fuel Cells. http://americanhistory.si.edu/fuelcells/alk/ alk3.htm (accessed February 11, 2010).

5. Zhang, J.; Sasaki, K.; Sutter, E.; Adzic, R. R. Stabilization of Platinum Oxygen-Reduction Electrocatalysts Using Gold Clusters. Science 2007, 315, 220-222.

6. Gong, K.; Yu, P.; Su, L.; Xiong, S.; Mao, L. Polymer-Assisted Synthesis of Manganese Dioxide/Carbon Nanotube Nanocomposite with Excellent Electrocatalytic Activity toward Reduction of Oxygen. J. Phys. Chem. C 2007, 111, 1882-1887.

7. Che, G.; Lakshmi, B. B.; Fisher, E. R.; Martin, C. R. Carbon Nanotubule Membranes for Electrochemical Energy Storage and Production. Nature 1998, 393, 346-349.

8. Yang, J.; Liu, D.-J.; Kariuki, N. N.; Chen, L. X. Aligned Carbon Nanotubes with Built-in $\mathrm{FeN}_{4}$ Active Sites for Electrocatalytic Reduction of Oxygen. Chem. Commun 2008, 329-331.

9. Kongkanand, A.; Kuwabata, S.; Girishkumar, G.; Kamat, P. Single-Wall Carbon Nanotubes Supported Platinum Nanoparticles with Improved Electrocatalytic Activity for Oxygen Reduction Reaction. Langmuir 2006, 22, 2392-2396.

10. Collman, J. P.; Devaraj, N. K.; Decréau, R. A.; Yang, Y.; Yan, Y.-L.; Ebina, W.; Eberspacher, T. A.; Chidsey, C. E. D. A Cytochrome c Oxidase Model Catalyzes Oxygen to Water Reduction under Rate-Limiting Electron Flux. Science 2007, 315, 1565-1568.

11. Winther-Jensen, B.; Winther-Jensen, O.; Forsyth, M.; MacFarlane, D. R. High Rates of Oxygen Reduction over a Vapor Phase-Polymerized PEDOT Electrode. Science 2008, 321, 671-674.

12. Huang, S.; Dai, L.; Mau, A. W. H. Patterned Growth and Contact Transfer of Well-Aligned Carbon Nanotube Films. J. Phys. Chem. B 1999, 103, 4223-4227.

13. Geim, A. K.; Novoselov, K. S. The Rise of Graphene. Nat. Mater. 2007, 6, 183-191.

14. Tung, V. C.; Allen, M. J.; Yang, Y.; Kaner, R. B. HighThroughput Solution Processing of Large-Scale Graphene. Nat. Nanotechnol. 2009, 4, 25-29.

15. Robinson, J. T.; Zalalutdinov, M.; Baldwin, J. W.; Snow, E. S.; Wei, Z.; Sheehan, P.; Houston, B. H. Wafer-Scale Reduced Graphene Oxide Films for Nanomechanical Devices. Nano Lett. 2008, 8, 3441-3445.

16. $\overline{\mathrm{Wu}}$, J.; Pisula, W.; Müllen, K. Graphenes as Potential Material for Electronics. Chem. Rev. 2007, 107, 718-747.

17. Kim, K. S.; Zhao, Y.; Jang, H.; Lee, S. Y.; Kim, J. M.; Kim, K. S.; Ahn, J. H.; Kim, P.; Choi, J. Y.; Hong, B. H. Large-Scale Pattern Growth of Graphene Films for Stretchable Transparent Electrodes. Nature 2009, 457, 706-710.

18. Reina, A.; Jia, X.; Ho, J.; Nezich, D.; Son, H.; Bulovic, V.; Dresselhaus, M. S.; Kong, J. Large Area, Few-Layer Graphene Films on Arbitrary Substrates by Chemical Vapor Deposition. Nano Lett. 2009, 9, 30-35.

19. Wei, D.; Liu, Y.; Wang, Y.; Zhang, H.; Huang, L.; Yu, G. 
Synthesis of N-Doped Graphene by Chemical Vapor Deposition and Its Electrical Properties. Nano Lett. 2009, 9, 1752-1758.

20. Xu, Y.; Bai, H.; Lu, G.; Li, C.; Shi, G. Flexible Graphene Films via the Filtration of Water-Soluble Noncovalent Functionalized Graphene Sheets. J. Am. Chem. Soc. 2008, 130, 5856-5857.

21. Li, X.; Zhang, G.; Bai, X.; Sun, X.; Wang, X.; Wang, E.; Dai, H. Highly Conducting Graphene Sheets and Langmuir-Blodgett Films. Nat. Nanotechnol. 2008, 3, 538542.

22. Valles, C.; Drummond, C.; Saadaoui, H.; Furtado, C. A.; He, M.; Roubeau, O.; Ortolani, L.; Monthioux, M.; Penicaud, A. Solutions of Negatively Charged Graphene Sheets and Ribbons. J. Am. Chem. Soc. 2008, 130, 15802-15804.

23. Novoselov, K. S.; Jiang, D.; Schedin, F.; Booth, T. J.; Khotkevich, V. V.; Morozov, S. V.; Geim, A. K. TwoDimensional Atomic Crystals. Proc. Natl. Acad. Sci. U.S.A. 2005, 102, 10451-10453.

24. Ferrari, A. C.; Meyer, J. C.; Scardaci, V.; Casiraghi, C.; Lazzeri, M.; Mauri, F.; Piscanec, S.; Jiang, D.; Novoselov, K. S.; Roth, S.; et al. Raman Spectrum of Graphene and Graphene Layers. Phys. Rev. Lett. 2006, 97, 187401-1-4.

25. Baskin, Y.; Meyer, L. Lattice Constants of Graphite at Low Temperatures. Phys. Rev. 1955, 100, 544.

26. Gogotsi, Y.; Libera, J. A.; Kalashnikov, N.; Yoshimura, M. Graphite Polyhedral Crystals. Science 2000, 290, 317-320.

27. Xie, Y.; Sherwood, P. M. A. Ultrahigh Purity Graphite Electrode by Core Level and Valence Band XPS. Surf. Sci. Spectra 1993, 1, 367-372.

28. Chen, Q.; Dai, L.; Gao, M.; Huang, S.; Mau, A. Plasma Activation of Carbon Nanotubes for Chemical Modification. J. Phys. Chem. B 2001, 105, 618-622, and reference cited therein.

29. Wang, X.; Li, X.; Zhang, L.; Yoon, Y.; Weber, P. K.; Wang, H.; Guo, J.; Dai, H. N-Doping of Graphene Through Electrothermal Reactions with Ammonia. Science 2009, 324, 768-771.

30. Wei, D.; Liu, Y.; Wang, Y.; Zhang, H.; Huang, L.; Yu, G. Synthesis of N-Doped Graphene by Chemical Vapor Deposition and Its Electrical Properties. Nano Lett. 2009, 9, 1752-1758.

31. Collins, P. G.; Bradley, K.; Ishigami, M.; Zettl, A. Extreme Oxygen Sensitivity of Electronic Properties of Carbon Nanotubes. Science 2000, 287, 1801-1804.

32. Yang, Z.; Xia, Y.; Mokaya, R. Aligned N-Doped Carbon Nanotube Bundles Prepared via CVD Using Zeolite Substrates. Chem. Mater. 2005, 17, 4502-4508.

33. Kim, S. Y.; Lee, J.; Na, C. W.; Park, J.; Seo, K.; Kim, B. N-doped Double-Walled Carbon Nanotubes Synthesized by Chemical Vapor Deposition. Chem. Phys. Lett. 2005, 413, 300-305.

34. Maldonado, S.; Stevenson, K. J. Direct Preparation of Carbon Nanofiber Electrodes via Pyrolysis of Iron(II) Phthalocyanine: Electrocatalytic Aspects for Oxygen Reduction. J. Phys. Chem. B 2004, 108, 11375-11383.

35. Ayala, P.; Gruneis, A.; Gemming, T.; Grimm, D.; Kramberger, C.; Rmmeli, M. H.; Freire, F. L.; Kuzmany, H.; Pfeiffer, R.; Barreiro, A.; et al. Tailoring N-Doped Single and Double Wall Carbon Nanotubes from a Nondiluted Carbon/Nitrogen Feedstock. J. Phys. Chem. C 2007, 111, 2879-2884.

36. Morant, C.; Andrey, J.; Prieto, P.; Mendiola, D.; Sanz, J. M.; Elizalde, E. XPS Characterization of Nitrogen-Doped Carbon Nanotubes. Phys. Stat. Sol. A 2006, 203, 1069-1075.

37. Tammeveski, K.; Tenno, T.; Claret, J.; Ferrater, C. Electrochemical Reduction of Oxygen on Thin-Film Pt Electrodes in $0.1 \mathrm{M} \mathrm{KOH}$. Electrochim. Acta 1997, 42, 893897.

38. Yu, E. H.; Scott, K.; Reeve, R. W. Electrochemical Reduction of Oxygen on Carbon Supported Pt and Pt/Ru Fuel Cell Electrodes in Alkaline Solutions. Fuel Cells 2003, 3, 169-176.
39. Arico, A. S.; Srinivasan, S.; Antonucci, V. DMFCs: From Fundamental Aspects to Technology Development. Fuel Cells 2001, 1, 133-161.

40. Cui, H.-F.; Ye, J.-S.; Liu, X.; Zhang, W.-D.; Sheu, F.-S. Pt-Pb Alloy Nanoparticle/Carbon Nanotube Nanocomposite: A Strong Electrocatalyst for Glucose Oxidation. Nanotechnology 2006, 17, 2334-2339.

41. Dato, A.; Radmilovic, V.; Lee, Z.; Phillips, J.; Frenklach, M. Substrate-Free Gas-Phase Synthesis of Graphene Sheets. Nano Lett. 2008, 8, 2012-2016.

42. Emtsev, K. V.; Bostwick, A.; Horn, K.; Jobst, J.; Kellogg, G.L.; Ley, L.; McChesney, J. L.; Ohta, T.; Reshanov, S. A.; Röhrl, J.; et al. Towards Wafer-Size Graphene Layers by Atomspheric Pressure Graphitization of Silicon Carbide. Nat. Mater. 2009, 8, 203-207. 